\title{
Respuesta a la carta al editor publicada en el Vol. 23 Núm. 1 de 2021
}

\author{
Elvia Peña-Marcial1 orcid.org/0000-0003-1232-6000 \\ Lorena Inés Bernal-Mendoza1 orcid.org/0000-0002-1799-9522 \\ Leticia Reyna-Avila' ${ }^{1}$ orcid.org/0000-0001-9862-4062 \\ Rodrigo Pérez-Cabañas ${ }^{1}$ orcid.org/0000-0002-3417-2308
}

1. Docentes investigadores de la Escuela Superior de Enfermería No. 1, Universidad Autónoma de Guerrero. Chilpancingo, México

El proceso del envejecimiento del organismo humano no debe reducirse al proceso biológico, debe analizar el contexto del hombre como un ser biológico, cultural, social, mental y espiritual integradamente(1).

Los términos vejez, anciano, senectud, adulto mayor, se utilizan para dirigirse a las personas que llegan a más de seis décadas de vida, pero no sólo el nombre ha cambiado, sino que también se han presentado cambios en las condiciones de salud, de vida y en el trato que reciben; el interés por la vejez, los procesos de envejecimiento y la calidad de vida, se han convertido en temas de investigación a lo largo de la historia de la humanidad.

Estudiar las características y cambios asociados al proceso de envejecimiento, es fundamental para conocer la calidad de vida en esta etapa, principalmente en el área de la salud, es decir la percepción de bienestar en los adultos mayores; incluyendo los factores sociales, económicos y personales.

Al medir calidad de vida (CDV) se debe considerar la percepción del ser humano a nivel individual y colectivo, que diversifica la concepción que pudiera ser el resultado de un estado actual vivido.

La CDV ha permitido distinguir resultados relevantes en salud, derivado de las investigaciones tempranas en bienestar subjetivo y satisfacción con la vida. Es un constructo multidimensional, con el mínimo de dominios físicos, emocionales y de bienestar social(2).

Existen otros términos para designar calidad de vida como satisfacción con la vida, bienestar subjetivo, bienestar, autoreporte en salud, estado de salud, salud mental, felicidad, ajuste, estado funcional y valores vitales(3).

Las diferentes percepciones como es definido o utilizado este concepto conlleva a diversos problemas, por un lado, no existen parámetros universales de una óptima o buena calidad de vida, ya que los estándares con los que se evalúa son distintos a nivel individual y colectivo(4). Puede ser vista como satisfacción personal, es decir la unificación de la satisfacción con las dimensiones de la vida; o puede ser el bienestar subjetivo y dejar de lado las condiciones externas de vida(3).

De ahí que cuando se pretende dar una definición de calidad de vida, se observan múltiples acercamientos y se encuentra una indefinición del término, el cual se asocia, por un lado, con nivel de vida o estilo de vida, y por otro, con bienestar y salud, satisfacción e incluso con felicidad(5).

La Organización Mundial de la Salud, define la calidad de vida como "la percepción que un individuo tiene de su lugar en la existencia, en el contexto de la cultura y del sistema de valores en los que vive y en relación con sus objetivos, expectativas, normas, e inquietudes. Se trata de un concepto muy amplio que está influido de modo complejo por la salud física del sujeto, su estado psicológico, su nivel de independencia, sus relaciones sociales, así como su relación con los elementos esenciales de su entorno"(1). 
También es considerada como un estado de bienestar físico, social, emocional, espiritual, intelectual y ocupacional que le permite al individuo satisfacer apropiadamente sus necesidades individuales y colectivas. La esencia de la calidad de vida en realidad es subjetiva; cada cultura, cada sociedad con sus diferentes valores y las connotaciones socioculturales, la evalúan desde diferentes puntos de vista; puede definirse de acuerdo con la etapa de vida(6).

La buena percepción del estado de salud, el nivel educativo alcanzado, la economía y el entorno social favorables, el grado de satisfacción que se experimenta y el logro de los objetivos individuales, están íntimamente asociados a una experiencia positiva del envejecimiento y la longevidad satisfactoria. La calidad de vida en los adultos mayores involucra la seguridad económica y la inclusión social y necesariamente el apoyo social y familiar a las personas que desean continuar viviendo en la comunidad en sus hogares, ser cuidadas en familia, que conlleva el apoyo material y afectivo a los familiares que, con distintos grados de implicación, participan en la acción de cuidar(6).

Se analizaron estos modelos teóricos y se optó por retomar la percepción del sujeto investigado para determinar la calidad de vida a partir del cuestionario de Salud SF-36 Versión 2 en las que se valoró la función física, rol físico, dolor corporal, salud general, vitalidad, función social; rol emocional y salud mental, además incluye el concepto general de cambios en la percepción del estado de salud actual y en el año anterior, delimitando así la investigación.

Sin duda los lineamientos planteados en la carta al editor son parte del abordaje para estudiar la calidad de vida en esta población, tomando como punto de referencia lo que establece la metodología a implementar, es decir en un proceso investigativo en que la rigurosidad científica permite que los hallazgos sean los que den pauta a nuevas investigaciones en los diferentes ámbitos, dando respuesta a las necesidades expresadas por la población de estudio.

Los instrumentos de medición cuantitativa nos aportan la rigurosidad para medir y estandarizar los resultados de un fenómeno de interés; no obstante, sería prioritaria la apertura a nuevos enfoques que permitan la expresión real de los individuos acerca del significado que tiene para ellos la calidad de vida desde sus experiencias a lo largo de una trayectoria; es decir dar la expresión a partir de una metodología diferente como es la cualitativa.

Conflicto de intereses: Ninguno declarado por los autores.

\section{Referencias}

1. Aponte Daza VC. Calidad de vida en la tercera edad. Ajayu [Internet]. 2015 [citado el 14 de diciembre de 2021];13(2):152-82. Disponible en: http://www.scielo.org.bo/scielo.php?script=sci_arttext\&pid=S2077-21612015000200003\&lng=es\&nrm=iso

2. García Ramírez JA, Vélez Álvarez C. Determinantes sociales de la salud y la calidad de vida en población adulta de Manizales, Colombia. Rev Cub Salud Publica [Internet]. 2017 [citado el 14 de diciembre de 2021];43(2):191-203. Disponible en: http://scielo.sld.cu/scielo.php?script=sci_arttext\&pid=S0864-34662017000200006\&lng=es

3. Urzúa A, Caqueo-Urizar A, Beyle C. Procesos cognitivos vinculados al autoreporte de la calidad de vida: el efecto de la comparación en población adulta [Internet]. Interciencia. 2018 [citado el 14 de diciembre de 2021]. Disponible en: https://www.interciencia.net/wp-content/uploads/2018/05/351-URZUA-43_5.pdf

4. González Tovar J, Garza Sánchez RI. Primera revisión del Cuestionario de Calidad de Vida para Adultos Mayores en Comunidad ccvamc-62. CIENC ergo sum [Internet]. 2016;23(1):17-25. Disponible en: https://www.redalyc.org/articulo.oa?id=10444319003

5. Wong Ayala JN. Determinantes de la salud en adultos mayores del "Club Adulto Mayor” _ Huacho, 2017 [Tesis de grado]. Chimbote, Perú: Universidad Católica los Ángeles de Chimbote; 2018. Disponible en: http://repositorio.uladech.edu.pe/handle/123456789/1970

6. Loor López CL, Rodríguez Álava JB. El abandono del adulto mayor y su incidencia en su estado emocional en el Centro Gerontológico Casa Hogar Caleb de la ciudad de Portoviejo en la provincia de Manabí en el año 2018. Caribeña de Ciencias Sociales [Internet]. 2018 [citado el 14 de diciembre de 2021];(diciembre). Disponible en: https://www.eumed.net/rev/caribe/2018/12/abandono-adultomayor.html 